Int. J. Electrochem. Sci., 12 (2017) $7227-7239$

International Journal of

ELECTROCHEMICAL

SCIENCE

www.electrochemsci.org

\title{
One-step Preparation of Alkaline Lignin-based Activated Carbons with Different Activating Agents for Electric Double Layer Capacitor
}

Yan Wu, Jing-Pei Cao*, Zhi-Qiang Hao, Xiao-Yan Zhao ${ }^{* *}$, Qi-Qi Zhuang, Jun-Sheng Zhu, Xing-Yong Wang, Xian-Yong Wei

Key Laboratory of Coal Processing and Efficient Utilization (Ministry of Education), China University of Mining \& Technology, Xuzhou 221116, Jiangsu, China

*E-mail: caojingpei@cumt.edu.cn; beyondcao@hotmail.com; beyondcao_2000@163.com

${ }^{* *}$ E-mail: zhaoxiaoyan@cumt.edu.cn

doi: $10.20964 / 2017.08 .01$

Received: 3 May 2017 / Accepted: 29 May 2017 / Published: 12 July 2017

Different structured activated carbons (ACs) were made from lignin (alkaline) by one-step activation. Using $\mathrm{ZnCl}_{2}, \mathrm{KOH}$ and $\mathrm{K}_{2} \mathrm{CO}_{3}$ as activating agents and the effect of activating agents on the electrochemical properties of the ACs for electric double layer capacitor (EDLC). The ACs prepared by the three kinds of activating agents are mainly microporous, while the $\mathrm{ZnCl}_{2}$-activated and $\mathrm{KOH}$ activated ACs contain mesoporous through the nitrogen adsorption-desorption test. All the ACs used as electrode for EDLC showed excellent cyclability. The small amount of $\mathrm{CO}_{2}$ produced by $\mathrm{K}_{2} \mathrm{CO}_{3}$ decomposition involved in the activation reaction and a series of reactions between carbon of lignin and $\mathrm{K}_{2} \mathrm{CO}_{3}$, giving a $\mathrm{AC}$ with the maximum specific surface area of $1585 \mathrm{~m}^{2} \mathrm{~g}^{-1}$, and the best specific capacitance $\left(\mathrm{C}_{\mathrm{s}}\right)$ performance of $263.46 \mathrm{~F} \mathrm{~g}^{-1}$ at the current density $40 \mathrm{~mA} \mathrm{~g}^{-1}$, using a two-electrode system. The results indicate that the $\mathrm{K}_{2} \mathrm{CO}_{3}$ as activating agent to prepared lignin-based $\mathrm{AC}$ applied in EDLC is appropriate.

Keywords: Activated carbon; Activating agent; Lignin; EDLC; Specific capacitance.

\section{$\underline{\text { FULL TEXT }}$}

(C) 2017 The Authors. Published by ESG (www.electrochemsci.org). This article is an open access article distributed under the terms and conditions of the Creative Commons Attribution license (http://creativecommons.org/licenses/by/4.0/). 